\title{
Team and Project Work in Engineering Practices
}

\section{Anders Buch'}

Associate Professor, Department of Learning and Philosophy, Aalborg University Copenhagen, Copenhagen, Denmark

\section{Vibeke Andersen}

Associate Professor, Department of Learning and Philosophy, Aalborg University Copenhagen, Copenhagen, Denmark

\begin{abstract}
In this article, we investigate teamwork amongst professionals in engineering consultancy companies in order to discern how teamwork affects the collaboration and work practices of the professionals. The article investigates how professional engineering practices are enacted in two engineering consultancy companies in Denmark where teamwork has been or is an ideal for organizing work. Through a practice-based lens, the article sets out to investigate, firstly, how discourses about team and project work affect engineering work practices; secondly, how technologymediated management is reconciled in teamwork practices; and thirdly, how team and project work affect engineering professionalism and collaborative work practices. A practice theoretical framework informs the analysis. Teamwork is investigated as a phenomenon enacted through the sayings, doings and relatings of practitioners in landscapes of practices and the interconnectedness of the practices is traced through the setup of specific ecologies in the sites.
\end{abstract}

\section{KEY WORDS}

Team and project work / practice theory / engineering practice

DOI

10.19154/njwls.v5i3a.4832

\section{Introduction}

$t$ is the aim of this article to investigate teamwork among professionals in engineering consultancy companies in order to discern how teamwork affects the collaboration and work practices of the professionals. The paper investigates how professional engineering practices are enacted in two engineering consultancy companies in Denmark where 'teamwork' has been or is an ideal for organizing work.

Team and project work is both a new and an old phenomenon. It is evident that people always have cooperated and coordinated work to achieve their goals and solve problems. But team and project work has-in the post-industrial era-also developed into the preferred mode of organizing work in many companies and public institutions. It is not only considered to be an effective mode of production but also an ideal mode to spur innovative, creativity, and knowledge generation/sharing. In recognition of the complexity and knowledge-intensive character of the challenges facing companies and organizations today team and project work models are adopted as the appropriate response

\footnotetext{
${ }^{1}$ E-mail: buch@learning.aau.dk
} 
(e.g. Alvesson 2004). The problems encountered by industry, in the healthcare sector, or in the educational sector call for an integration of diverse disciplinary knowledge and skills. Professionals from different strands and knowledge domains join up in order to cope with pressing problems. Interdisiplinarity and transdisciplinarity (Frodeman et al. 2012) are ideals for coping with complex, wicked, real-life problems, and team and project work are often seen as the preferred mode of organizing to achieve this.

In addition, team and project work is often considered to produce cohesion and identity among professionals in organizations, to level disciplinary, bureaucratic, and organizational barriers and thus enrich the work environment in general. Teamwork is thus often considered to stimulate personal as well as professional growth, autonomy, collectivity, solidarity, and wellbeing.

But contrary to this rosy picture of team and project work critical research has pointed to other less attractive consequences of teamwork (e.g. Baker 1999; Haregraves 2000; Heckscher \& Adler 2006). The team can in fact also become a locus for (disciplinary) conflicts, unresolved organizational tensions, conflicting demands, and processes of group pressure, marginalization, and control—a convenient decentralized locus to deposit organizational tensions. The ideals of inter- and transdisciplinarity of teamwork often pay little attention to the professional traditions and professional identities that team members bring to teamwork (Buch \& Andersen 2013a). Professionals are viewed as 'human resources' by HR managers and project managers and teams are composed according to the professionals 'competencies' to match 'team competence profiles' that are required to solve assignments and projects. Scant attention is given to traditional professional work routines, procedures, conventions, and practices in this rationalization of team formations. As a consequence, teamwork is often loaded with ambiguities, dilemmas, tensions, and conflicting narratives in relation to what should/ought to constitute 'professional' work, which procedures should be perused, how to frame and solve problems in the work process, and so on.

In engineering, consultancy team and project work goes back a long time. Projects are traditionally established around tasks and coordinated by project managers. Project members are assigned due to their expertise in specific technical fields that match specific tasks within the project. Teams are formed on a temporary and ad hoc basis and they typically follow the lifetime of the project. Characteristically, engineering work is very diverse and specialized and draws upon a broad variety of (scientific) disciplines spanning from physics and chemistry to logistics and management. New groups of professionals with academic degrees in the social sciences are entering engineering consultancy companies by increasing numbers and employees are supposed to collaborate with colleagues with very different professional training backgrounds, as well as customers and citizens. Projects are typically initiated in accordance with costumers' needs and the project managers are the connecting links between the customers and the project organization. The employees are often organized in complex matrix organizations incorporating divisions, sections, project teams, and so on. This complex setup installs an organizational logic (Stark 2009) with minimal formal vertical layers but with extensive heterarchical and more informal structures where the employees are held accountable to standards, values, deadlines, and invoicing systems.

Our discussion of teamwork in engineering practices will proceed in five steps. Firstly, we will specify three research questions that have guided our investigation and we will position our research perspective within practice-based studies. We will then, secondly, present the empirical material that we have produced in two sites: ethno- 
graphic accounts of engineering practices in two consultancy companies. The following discussion will then, thirdly, consider the ecologies of the practices in order to discern how the doings, sayings, and relatings of the practitioners in combination with the material arrangements configure practice. Fourthly, we will continue our discussion of the practices in order to explicitly reflect on the role of teamwork in engineering practices and how teamwork as an ideal and management concept affects relations in engineering practices. Fifthly, we will conclude our discussion.

\section{Focus and approach}

Through multi-sited ethnographic and practice-based studies (Gherardi 2012; Kemmis et al. 2014; Marcus 1995; Schatzki 2002), this article sets out to investigate how teamwork is being 'done' and practiced in two engineering consultancy companies. We bring together our own ethnographic studies of engineering work practices in two Danish engineering consultancy companies (Buch \& Andersen 2013b, Buch forthcoming). In these different sites, we show how team and project work mediate relations within organizations and how team members experience the impact of teamwork in relation to their professional backgrounds and outlooks. By paying attention to how teamwork is materially and discursively enacted in these different sites, we are addressing three research questions:

- How do discourses about team and project work affect engineering work practices?

- How is technology-mediated management reconciled in teamwork practices?

- How does team and project work affect engineering professionalism and collaborative work practices?

In our study, collaboration in engineering work practices has been studied as 'sites' in Schatzki's perspective (Schatzki 2002) and we have been inspired by Kemmis et al.'s (2014) and Kemmis and Grootenboer (2008) notion of Practice Architectures in order for us to discern the doings, sayings, and relating that constitute the practices within the fieldsites. In line with Schatzki's perspective, we do not intend to use the different sites to make comparisons, but instead we explore how 'teamwork' is taken up, reenacted, and practiced in different ways in the sites according and in relation to the specificities of the practice architectures and practice traditions that encapsulates the happenings and history of the practices. This allows us to investigate how cross-affiliations and overlaps of culturaldiscursive, material-economic, and social-political arrangements are weaved together and intertwined, but the approach also helps us make visible differences and contrasts in lending 'meaning' to the dominant discourse about teamwork. A site is not only delimited by its physical localization. More generally, a 'site' is a locality where something-a social phenomenon like team and project work-is or takes place (Schatzki 2002, 64). The physical location is of importance in the sense that social phenomena always transpires in objective space-time, but in an important sense, the site transgresses objective spacetime. The teleological location ${ }^{1}$, that is, how actors are attuned to and comports with a phenomenon, in significant ways specify how actors relate to the phenomenon and signify a 'Verweisungsganzheit' (Heidegger 1927/2010). This helps contextualize social activity.

The production of our empirical material has benefitted from Kemmis et al.'s (2014) elaboration of Schatzki's (2002) theoretical and methodological framework and we use 
their 'table of invention' (Fig. 1) to structure and present our findings. Our descriptions of the practices thus not only pay attention to the actual sayings, doings, and relatings of the actors involved in the practices, we also discern how these sayings, doings, and relatings are framed within the projects of the actors (the teleoaffective structures); how they are shaped by the dispositions (or practical understandings) of the actors; how the practices transpire in practice landscapes (or among rules and material arrangements surrounding the actors); and how the practices are informed by practice traditions (or general understandings) in which the actors are embedded. Engineering practices and engineering culture is thus being (re)produced within sites and through practices that can only be understood properly by reflecting on the doings, sayings, and relating of the practitioners and how they are configured in specific constellations in time and space and in history. Attention must be given to the discursive and historical preconditions of the sites as well as the material arrangements that prefigure the practices. Furthermore, it is necessary to reflect on how power-relations and social-political arrangements shape the way practitioners relate to one another. It is thus the ambition to analyze the sites by using a practice-based lens developed by Kemmis et al. This methodology honors the complexity and heterogeneity of the engineering practices under study and lends us practical methods to track and propel our investigations. Kemmis et al. draw our attention to the dual composition of practices and how this duality constitutes both individual agency and structure in social activity. Practices thus have both an individual and an extra-individual dimension that simultaneously produce individual knowledge and identity on the one hand and social structures on the other hand. In this way, the practice perspective challenges us to reflect both the individual and the social elements in ongoing activities.

Although sayings, doings, and relatings are thoroughly interwoven in activity timespace, we will, for analytical purposes, present our ethnographic material according to

Figure I: Elements of practices and practice architectures in the site (adaptation of Kemmis et al. 2014, p. 38-39).

\begin{tabular}{|c|c|c|c|}
\hline \multicolumn{4}{|c|}{ Individual side $\leftarrow$ Practice $\rightarrow$ Extra-individual side } \\
\hline \multicolumn{2}{|c|}{$\begin{array}{l}\text { Projects/teleoaffective structures } \\
\text { How purposes and intentions expressed by } \\
\text { practitioners direct activity }\end{array}$} & \multicolumn{2}{|c|}{$\begin{array}{l}\text { Practice landscapes } \\
\text { How practitioners and objects are enmeshed and } \\
\text { entangled in activity and how materiality, rules, and } \\
\text { procedures prefigure actions by infrastructural } \\
\text { sedimentations }\end{array}$} \\
\hline $\begin{array}{l}\text { Practitioners' character- } \\
\text { istic 'sayings' }\end{array}$ & \multicolumn{2}{|c|}{$\begin{array}{l}\leftarrow \text { How 'sayings' performatively enacts a practice in } \\
\text { semantic space through language } \rightarrow\end{array}$} & $\begin{array}{l}\text { Cultural-discursive ar- } \\
\text { rangements }\end{array}$ \\
\hline $\begin{array}{l}\text { Practitioners' character- } \\
\text { istic 'doings' }\end{array}$ & \multicolumn{2}{|c|}{$\begin{array}{c}\leftarrow \text { How 'doings' enacts a practice through the } \\
\text { medium of activity and work } \rightarrow\end{array}$} & $\begin{array}{l}\text { Material-economic ar- } \\
\text { rangements }\end{array}$ \\
\hline $\begin{array}{l}\text { Practitioners' } \\
\text { characteristic } \\
\text { 'relatings' }\end{array}$ & \multicolumn{2}{|c|}{$\leftarrow$ How 'relatings' enact power and solidarity $\rightarrow$} & $\begin{array}{l}\text { Social-political } \\
\text { arrangements }\end{array}$ \\
\hline \multicolumn{2}{|c|}{$\begin{array}{l}\text { Dispositions/practical understandings } \\
\text { How actors are attuned to participate in practices, } \\
\text { how they have a 'feel for the game', and how they } \\
\text { know how to 'go-on': practical knowledge, skillful- } \\
\text { ness, and appraisal of specific values. }\end{array}$} & \multicolumn{2}{|c|}{$\begin{array}{l}\text { Practice traditions/general understandings } \\
\text { How current practice is enacted to reproduce } \\
\text { or transform the traditions and history of the } \\
\text { local practice or-more broadly_-in relation to } \\
\text { the traditions and history of practices that span } \\
\text { multiple sites. }\end{array}$} \\
\hline
\end{tabular}


the above conceptualization of practices. Kemmis et al.'s practice-lens helps us investigate how the dynamics of practices are brought about by the interplay of sayings, doings, and relatings and how activity is transformed into integrative practices (Schatzki 1996, p. 98 ff.) through practical understandings, teleoaffective structures, rules, and general understandings.

\section{The two empirical sites}

Our research was conducted in two Danish engineering consultancy companies-Sarix and Gitcela ${ }^{2}$. Sarix provides consulting services regarding environmental and energy issues, planning and construction of infrastructures, and developmental cooperation in relation to the third world. Around 1300 professionals-mainly engineers-are employed at Sarix. The headquarters of Sarix are situated in the vicinity of Copenhagen in Denmark, but Sarix also has local offices in other cities in Denmark and many employees are assigned to projects all over the world. Gitcela is another major Danish consultancy company. Once Gitcela considered itself an engineering consultancy company, but now its operations and specialisms also include other domains. Gitcela has expanded by acquiring other companies and integrating them in Gitcela as subunits. Besides traditional engineering consultancy services, Gitcela thus provides consultancy in relation to brewery, food, work environment facilitation, health and safety, and more. Around 700 persons are employed in Gitcela-many of them with a background in engineering, but also many with other professional backgrounds.

The ethnography conducted in Sarix gravitates around a small team (four members-Nille, Sebastian, John, and Henrik) that worked with the development and promotion of a new product: Carbon emission accounts. We have had the opportunity to follow the team for almost a year. During this period, we studied their publications and work notes, conducted participatory observations, formal and informal interviews, and worked with generative methods of investigation. In addition, we have had the opportunity to identify and interview a number of actors adjacent to the team and individuals with opinions on engineering and engineering competencies in relation to environmental work. The other ethnography follows a small project in Gitcela. The project aimed to develop a public website for janitors and in particular the project manager in the different phases of the project over 1 year. We were introduced to the project in its early stages and witnessed how the project manager-Morten-was assigned his role. By following the project manager around-during meetings with colleagues, negotiating with a communication bureau, workshops with user groups, and so on-we were able to observe how the work practices unfolded, and in subsequent interviews, we had the project manager reflect on what was at stake during the interactions. ${ }^{3}$

\section{Engineering practices and practice architectures in Sarix}

\section{Relating and social-political arrangements}

Copenhagen was the hosting city of the international climate summit COP15 in 2009. This event spurred a lot of public and political attention about climate changes due to 
the emission of greenhouse gases into the atmosphere. Until this event, the conservative Danish government had given little focus to climate problems. In fact, the Danish government sponsored the prominent 'climate change denier' Bjørn Lomborg and had made dramatic cuts in the public environmental initiatives. But in the preparation phase of the summit in Copenhagen, this all changed. Suddenly, the Danish government withdrew its sponsorship to Lomborgs research and recognized the severe climate challenges we are facing. This change of policy toward the climate problems was accompanied by new visions about clean-tech and environmental services as drivers for economic growth and employment in Denmark. These vision and the high expectations in relation to achieving global agreements on climate issues raised an atmosphere of optimism and encouraged the companies within the environmental service sector to launch new initiatives. This is the backdrop for the initiatives taken by Sarix in 2008. The company decided to establish a new division with a focus on climate change. Previously, the company had been supplying services that were 'reactive' in relation to climate change-for example, planning and dimensioning infrastructure facilities that could deal with flooding. Now, a new division should develop 'proactive' climate solutions—solutions that could monitor and reduce emissions of greenhouse gases and document the 'carbon footprint' of consumers, households, products, companies, regions, and so on. A dedicated COO was put in charge of this new division. In general, this division was organized along a number of smaller teams that pursued different business solutions. The COO recruited a team of 'holistically minded' engineers that should develop new types of accounts that could specify business units' total 'carbon footprint' by measuring the direct and indirect emissions due to the unit's activities. He was struck by the fact that heating and transportation could only account for a fraction of the total carbon emission. Other components integral to companies manufacturing processes have a considerable impact that is not accounted for. The account should thus develop procedures that can measure the quantities of carbon emission due to a company's totality of activities. A law-enforced regulation of companies' carbon emissions would surely introduce emissions as an economic parameter. If climate quotas come to play an increasing role in the pursuit of emission reductions more accurate climate accounts should be developed in order for companies to monitor their footprints.

However, the climate summit turned out to be a disappointment. No global agreement was established and many criticized the Danish governments' handling of the negotiations taken place at the summit. The enthusiasm and optimism about the prospect of clean-tech industry and environmental service sector as drivers for economic growth faded. No prospects of regulation of companies' carbon emissions were in sight. Sarix's 'proactive' strategy was put on hold and the enthusiastic COO in charge of the strategy left the company in favor of a position within an environmental NGO. When we entered Sarix in 2011, the climate division was abolished and only a small group of four employees were engaged in developing and selling climate accounts. Although Sarix had given up the ambitious 'proactive' plan, the group insisted on upholding the status of a team that was dedicated to develop climate accounts. Their insistence was tolerated, but it was made clear to the team members that their activities should be profitableotherwise their jobs were in jeopardy. Each and every employee in Sarix (except employees in management positions and administration) should be able to refer $75-80 \%$ of his or her work hours to customer-financed projects. Time spent on other activities were considered 'unproductive' time. On a weekly basis, the employees at Sarix had to fill out 
an electronic time sheet and refer work hours to projects. It was evident to all that the four members of the team were not able to fulfill this requirement. An insufficient number of customers were interested in Sarix's climate accounts. So, to uphold the 'efficiency standard' and account for their individual fulfillment of the $75 \%$ profitable workload, the team members had to sign up for work in other 'reactive' projects within Sarix.

\section{Doings and material-economic arrangements}

Developing climate accounts essentially builds on connecting two elements: on the one hand the economic accounts of the companies and on the other hand emission tables based on diverse product groups. To give an example: If a significant figure in a company shows that X DKR has been spent on consumption of electricity, this number corresponds to a $\mathrm{CO}_{2}$ figure in the emission table. By analyzing the economic accounts, it is thus possible to determine the carbon footprint of a company. The challenging part of the work is to correlate the economic figures with the right categories of the emission tables. Uncertainty in climate accounts can be reduced by specifying and detailing the categories of the products that are being used in the companies. This specification of the products will make them match better with major posts in the economic accounts of the companies. A climate account for a hospital will, for example, be very imprecise if the expense for medicine is related to the broader category 'chemical' within the emission tables ('chemicals' being a category that will also include cleaning products). A better match will be made if the 'chemical' category can be broken down and the expenses to medicine related to the subcategory 'pharmaceutical products'. Economic accounts and emission tables thus become significant elements within engineering work in Sarix. The challenge consist of procuring detailed economic figures from the companies and securing that the most detailed and suitable categories from the emission tables are being used. These translations, classifications, and categorizations require that the engineers not only have profound knowledge about materials, chemistry, and accounting, but also that the engineers have good communication skills in order to interact with accountants and administrators in companies.

An important feature of the work practices in Sarix is the electronic time sheet. As mentioned earlier, the electronic time sheet links work time with profitability. This 'invoicing system' functions as an overarching management system that structures and guides the work activities in Sarix. Every employee is constantly looking for 'account numbers' where it is possible to bill some hours of work. Although this system causes many frustrations among the employee at Sarix and most of the engineers find it 'counter-productive' on a long-term basis, very few can imagine how work could be organized otherwise.

As previously mentioned, the team we were following had four members. John was in his mid-thirties and had a mixed technical/social science masters degree from one of the new 'progressive' universities in Denmark that structure students learning activities in accordance with principle of multi-disciplinary, problem-based, and project-oriented methods. He got the role of the informal leader of the team. He was representing the team in relation to the official management layers in Sarix, but he also took/was given the role of promoting climate accounts to potential customers in the private and public sector. Henrik was in his late-thirties and had earned a master degree in geology from University 
of Copenhagen. Before coming to Sarix, he had worked in different companies with the regulation and improvement of physical work environments. Henrik was considered to be the 'number-crusher' in the team and he was mainly occupied with desk-research in relation to the construction of the emission tables. Nille and Sebastian were both in their early-thirties and had engineering degrees in Innovation and Sustainability from the Technical University of Denmark. They were both recruited directly to the new climate division as two 'holistically minded' engineers. Nille and Sebastian each took care of a variety of job-tasks within the team. Their activities span from drafting promotional proposals for potential new customers to specifying Sarix's web-page in ways that would make it likelier for it to pup-up on Google-searches on 'climate accounts'. They were also engaged with the actual translation processes between economic accounts and climate tables. All of the team members recognize the work that they were doing as 'engineering work'-irrespective of the fact that some of the team members were not trained as engineers.

Every week, the team meets for a 2-3 hour meeting. The meetings take place in an informal atmosphere in the teams' common office. The participants are mostly concerned with making status on ongoing work, discussing new initiatives, and breaking new jobs down to 'work-packages' that can be assigned to the individual team members. Thus, the meetings function as a forum for the division of labor. The team members seldom negotiate over who's to do the specified work-it seems to follow automatically from the roles that the team members are positioned/position themselves in. More discussions are concerned with making sure that the work is distributed in a solidary way among the team members so that individuals-who are most in need of filling up their weekly time sheets with assignments—get the most 'chunks'.

The 'invoicing system' is thus impacting the division of labor in significant ways.

\section{Sayings and cultural-discursive arrangements}

Although the work with developing climate accounts was closely related to general discussions about sustainability and environmental support, these more general discussions cannot be traced in the unfolding of work practices in Sarix. This absence is striking when we take into account what we learned from life story interviews with the four team-members. Nille's and Sebastian's educational background in Innovation and Sustainability, John's political ambitions 'to do a difference' in regard to the environment, and Henrik's engagement in developmental activities in relation to The Third World were only revealed in the private and confidential interview setting. The work within the team and the discussions taken in team meetings were conducted within a very practical and instrumental discourse where the actual benefit and purpose of the climate accounts were never problematized or made explicit. Almost all work-related conversations and discussions were addressing organizational issues or issues concerning how to optimize marketing efforts to get more companies to adopt climate accounts. The concrete and technical questions about the development of climate accounts remained tacit and an individual matter. This kind of technical work-making the translations from economic accounts to emission tables-was done on a routine basis and not made a subject for collective discursive reflections.

Thus, the discussion in the team meetings revolved around questions about how to market the climate accounts in better ways. Sarix have longstanding and close relations 
to many public companies and institutions, but it seemed as if the market for selling climate accounts in the public sector had been exhausted. The team members had good contacts with engineers and planners within the public sector. Their contacts shared the professional enthusiasm for developing climate accounts that could function as a monitoring tool for environmental initiatives. When we interview a project engineer in a public company that had implemented the climate account concept that Sarix had developed, he told us that it was very much up to him to convince the board to adopt climate accounts. For his own part, he was already convinced about the benefits of the monitoring tool. The project engineer thus already shared the perspectives of the team and worked to advance the use of climate accounts. However, the situation is quite different in relation to private companies. It is very difficult to motivate private companies to develop climate accounts. Only a few private companies have adopted climate accounts as an element in CSR (Corporate Social Responsibility) strategies today. The team members had the opinion that legislative measures had to be taken in order to get more private companies to develop climate accounts-it was not sufficient to 'motivate' the CSR responsible officer. Trust was put in the new socialist government that came to power in the fall of 2011-but no legislation in relation to climate accounts has been introduced as this is written.

\section{Engineering practices and practice architectures in Gitcela}

\section{Relating and social-political arrangements}

We had the opportunity to follow the start-up of a small project that aimed to develop a public website for janitors (and others-for example, homeowners) who were concerned with new cellar practices-how to use and maintain cellars. In the summer of 2011, the Copenhagen area witnessed a massive rainfall that caused severe flooding problems and considerable numbers of cellars in private homes and apartment houses were damaged. Thus, an investment fund decided to establish a public web page that could primarily be used by janitors as a guide for reestablishing and maintaining their cellars. Morten-a newly employed engineer in Gitcela in his thirties-was assigned as a project manager of this small project. The objective of the assignment was-in collaboration with an external communication bureau-to gather professional knowledge about cellar maintenance. This knowledge should be transformed to guidelines that could be presented on a public web page. Morten should compile existing knowledge about cellar maintenance from the experts in Gitcela and from relevant external experts.

The website-project was a minor project in Gitcela. But we learned that it was quite typical of the way work was organized. Normally engineering projects are considered to be very structured and well defined with officially appointed project managers, project members, Gantt-charts, milestones, project committees, and so on. But that was not the case with this small project as with most other projects in Gitcela. Only major projects in Gitcela are run in this way. Morten consulted his colleagues and internal and external experts as the project progressed and asked them to consider and solve well bounded and confined problems-small 'work-packages' defined by Morten. Thus, Morten's colleagues in Gitcela were consulted sequentially and were not considered to take part in the general development of the project-they were more 
like individual subcontractors. They stepped in and out of the project and made incremental contributions on the basis of their professional specialisms and experiences from previous projects.

Morten was assigned to the project as project manager-not because he had specific experiences or knowledge about cellars, but specifically because he did not have any specific knowledge about 'cellars'. Morten is trained as an engineer, but his specialization has nothing to do with housing ventilation or any other engineering specialism relevant to the project. But he has an engineering degree from a Danish university that base its programs on the problem-based and project-structured learning model (PBL). Morten has thus learned to confront complex and ill-defined problems and work out solutions in small study teams formed around study projects. He is aware that his field of expertise lies somewhere else than most other engineers. The project-oriented approach from his university training has taught him to deal with complex problems in an unassisted way. To deal with the complexity, define the approach, and frame the problem that are supposed to be solved, he preferred to set up workshops and invite participants to give input. Morten does not consider this competence to be unique. It is something that anyone can learn easily, but he sees it as very effective in going about solving problems.

Morten was only recently employed in Gitcela. After finishing his master program in engineering, he took additional university courses in engineering subjects and finally enrolled in an industrial PhD-program in another company. However, he broke off his PhD-studies in order to start working in Gitcela. He considered this work to be more versatile, practical, and fulfilling. With under a year of experiences in Gitcela, Morten was put in charge of running the project. He had some good ideas about where to look for the relevant knowledge required for the project and how this knowledge should be disseminated, but he has no clear idea about the specificity of the kind of knowledge that should be gathered. When Morten was appointed project manager, he was free to consult colleagues in any way he saw fit. This freedom was only given to him because of the small size of his project. For bigger projects, the HR-department have developed a procedure for composing teams-in order to prevent 'gang-staffing'. 'Gang-staffing', that is, composing teams on the basis of personal relations and personal experiences, is a derogatory term used by management in Gitcela. 'Gang' in Danish means 'corridor' and 'gang-staffing', thus-in its more benign meaning - refers to an informal way of organizing. But it definitely also connotes the English meaning of 'gang'. By using this expression, the management indicates that the composition of teams ought to be based on more objective and rational criteria-such as individual competence profiles that can match the projects needs for competencies and general considerations about resource spending. When we entered Gitcela for the first time, management and HR had great ambitions to change the informal 'gang-staffing' way of organizing work to a more centralized and rational procedure. However, half a year later, it was difficult to trace the ambition in our interviews with HR-management. It had proven difficult to manage and control the manning of the projects-a lot of practical issues of logistics and personal relations turned out to make centralized project manning difficult. In addition, the employees tried to sidestep the procedure by understating the size of new projects in order to prevent being assigned HR-procedures of team and project formations. The employees preferred the traditional personal network approach. Management, however, never officially gave up the ambition.

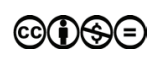




\section{Doings and material-economic arrangements}

The professionals at Gitcela also kept track of their time expenditure by registering on an invoicing system. But in contrast to what was the case in Sarix, the invoicing system did not play a prominent role in the mindsets of the project participants. Contrary to Sarix, there was a positive attitude toward the invoicing system. It was Morten's opinion that the invoicing system made it possible to be flexible in relation to the projects. The centralized invoicing system made the individual employee accountable to the company and not to their local sections-in a way the time system set the individual free. It was quite legitimate to consult colleagues across sections and ask for their assistance. And by offering hours, Morten could compensate colleagues for their contributions. At the end of each meeting or bilateral interaction, Morten typically mentioned how many hours were made available for the completion of the 'delivery' and how many hours had already been consumed. Normally, this did not cause any problems or conflicts. Maybe this was because of the projects size; maybe the colleagues just wanted to help the new project manager; or maybe the colleagues appreciated the transparency and flexibility of this procedure. We do not know. But we had the impression that most colleagues actually enjoyed helping out, and they were even willing to bring work to their homes in order to meet the deadlines agreed upon.

In fact, Morten kept track of time consumption by using his own electronic project management tool. He made very detailed registrations of time consumption, participant's contributions, expenditures, and the remaining budgeted resources. It came in handy when Morten were to negotiate and discuss the development of the project with the external communication bureau. When the bureau argued for changes in the work plan and changes in the division of responsibilities due to substantial and professional reasons, Morten referred to the complex spreadsheets and made it clear that changes were very difficult to implement.

\section{Sayings and cultural-discursive arrangements}

There seemed to be general agreement among the internal participants in the project that the engineers possessed the necessary professional knowledge that was required to make a good web page that could be informative to janitors. It was only a question of chunking the knowledge in the right proportions to the target audience of the web page. Thus, the engineers thought about the task as a process of cutting down the complexity of the engineering knowledge and presenting it in simple terms that could be understood by everyone. The engineers should so to speak take the view of the 'uninformed practitioner'. No specific technical terms could be taken for granted and IT skills could not be assumed. The engineers often joked about how few technical details non-engineers could actually comprehend-as opposed the complexity obtained within engineering discourse. In cooperation with the communication bureau, a couple of workshops with users (janitors) had been arranged in order to gain insights about the level of knowledge possessed by the users. But the engineers did not think much of it. Morten was of the opinion that the workshops did not provide new knowledgealready quite aware of the level of knowledge of the users. He only agreed to set up the workshops because it was part of the contract and the communication bureau insisted. 
Likewise, Morten did not sincerely appreciate that it takes special skills and knowledge to facilitate a workshop. With his background in PBL and project work, he was of the opinion that this could easily be learned. In general, the engineers thus made a collective discursive construction of what should be counted as specific (engineering) knowledge and what should be considered as general skills—-that everyone could easily acquire or maybe even already possessed.

Although our research at Sarix and Gitcela produced other interesting observations, space does not allow us to elaborate further on our observations. We will instead turn to a discussion where we will investigate the relations between the elements of the sites in order to point to some of the dynamics and processes that are at play in the practices.

\section{Ecologies of practices in engineering consultancy}

Our account makes it clear that 'teamwork' has an important role to play in both Sarix and Gitcela, although in very different ways. In Sarix, teamwork was introduced as an organizing principle that should support the 'proactive' and 'holistic' strategy introduced in 2008, but the team-structure was abolished when the strategy was abandoned. The team we followed was only a reminiscence of the old strategy: kept alive by the four dedicated 'holistic' engineers-in spite of the new organizing principles and, as we have explained, their efforts were in vain. The team-members could not find the time, resources, nor the organizational support to do proactive and holistic teamwork. In Gitcela, on the contrary, teamwork was introduced by management as a rationalizing principle for the allocation of human resources-but sidestepped by the engineers who preferred to stick to their traditional 'gang-staffing' methods of organizing. In our ethnographies, teamwork-understood as a means of organizing work—thus enters and affects engineering work practices in significant ways.

To understand how, we need to understand how practices are sustained, changed, and transformed, and how cross-field effects are produced between practices. We do not, however, have space to elaborate this point at length (for thorough practice theoretical accounts of 'change' see Schatzki 2010 and 2013); instead, we will draw on the notion of 'ecologies of practices' by Kemmis et al. to illustrate how practices are reproduced and changed in the midst of human activity. Kemmis and Mutton (2012, p. 15) define 'ecologies of practices' in the following way:

By ecologies of practice we mean distinctive interconnected webs of human social activities (characteristic arrangements of sayings, doings, and relatings) that are mutually-necessary to order and sustain a practice as a practice of a particular kind and complexity (for example, a progressive educational practice).

Practices thus coexist in sites and affect one another through the sayings, doings, and relatings of the practitioners. Different teleoaffective structures, the introduction of new rules and new material arrangements, the entrance of actors with other practical understandings, and carriers of other practice traditions can potentially or effectively contribute to alter the practice when introduced-or they might not be successful in doing so. The important thing to understand here is that practices are connected, intertwined, and nested in ecologies and that practices feed on one another in complex feedback processes

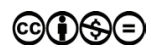


that can establish symbiotic relationships. Thus, changes in one practice have effects on other practices throughout the ecological system. New practices can thus alter practice ecologies and suffocate other practices-or the ecology might be strong enough to reject new practices and thus resist change (although it can be argued that status quo is in fact also an active enactment of practices and ecologies and that 'stasis' should thus not be conceived as fundamentally different from 'change', cf. Schatzki 2013, p. 37).

Our ethnographies describe how new practices are introduced into the practice ecologies of engineering consultancy companies. In Sarix, we saw how teamwork was introduced as a part of the 'holistic' and 'proactive' strategy. The strategy was propelled by top-management's insistence to change 'reactive' engineering practices in order to enter the new (presumably) attractive market for sustainability solutions. Furthermore, hiring 'holistic' engineers that were eager to underpin team-based work practices supported the strategy. However, as this discursive practice was not supported by the material-economic arrangements (e.g. the invoicing system) and the social-political arrangement (e.g. the management regime was displaced; environmental regulations were not imposed to the extent presumed), the strategy failed and was not enacted in the practice ecology of the company. Our remaining team struggled to enact the 'holistic' engineering practice, but was not successful in doing so. In Gitcela, teamwork was also introduced as a management strategy, but for other reasons than in Sarix. Here, management found 'gang-staffing' unproductive to allocate human resources effectively and used 'teamwork' as an appropriate organizing concept that could alter working practices. But, again, the discursive practice of the HR-managers did not survive in the practice ecology of the company-Morten and his colleagues ducked under the HR-managements policy radar and enacted engineering practice in more traditional 'gang-staffing' ways. Morten was determined to fulfill the project on time, within the settled budget and he needed to work with his engineering colleagues in flexible ways bringing in the specialized expertise just in time and only to the extent that was needed to solve the specific work-packages. The relationship he established with his colleagues in the project was guided by professionalism, efficiency, and a clear focus on fulfilling the project. Morten enacted the broader practice tradition of efficiency optimizing that is established in the engineering profession and that was locally sustained in Gitcela. For Morten, it was much more important to 'get the job done' than to become a part of HR-managements resource scheme. The overarching project in both Sarix and Gitcela was to earn a profit by delivering engineering consultancy services. This imperative was very clear to the engineers, as they were held accountable on an individual basis to fulfill their workloads. They tried to accommodate the imperative in different ways. As for Morten, the imperative was honored by sidestepping the HR-strategy and by pursuing the cellar project by traditional 'gang-staffing' means-the traditional and (among the engineers) preferred principle of organizing collective work processes in Gitcela. Here, the practice traditions of traditional professional engineering (e.g. individualism, efficiency, accomplishment) were supportive of this endeavor. In Sarix, on the contrary, the 'holistic' engineers tried to honor the imperative by other means, but without success. Here, the four engineers insisted to uphold the practice tradition of 'holistic' engineering (e.g. engaging in collaborative, innovative, sustainable, and 'proactive' work processes), but they were not able to reconcile it with the enforced technology-mediated management practices. Henrik faced the consequences of the invoicing system and slowly drifted away from the team. He engaged in more 'reactive' engineering projects in other divisions of Sarix in 
Figur 2: Practice ecology of engineering consultancy companies.

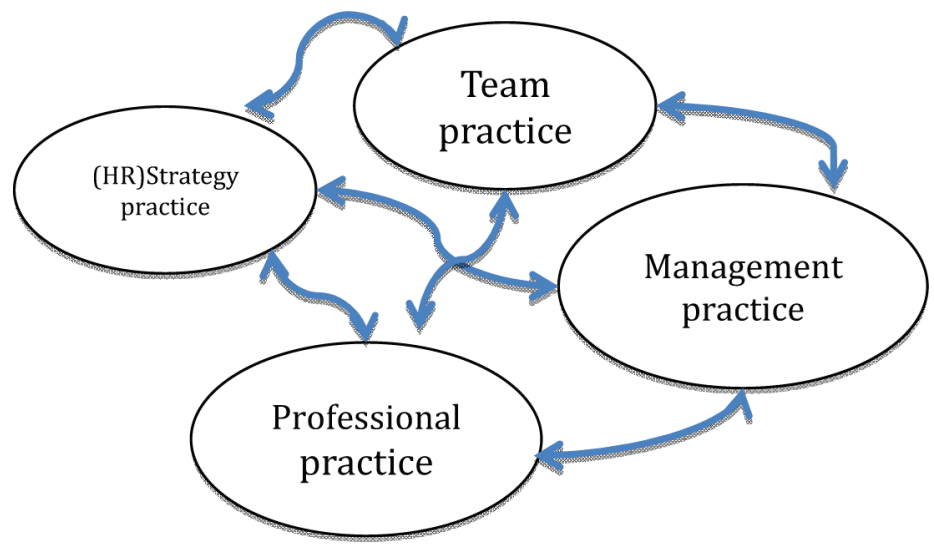

order to satisfy the invoicing requirements. John was more 'faithful' to his holistic engineering professionalism, but he had to start working part time and supplement his job with teaching activities. Sebastian and Nille kept their full-time positions but 'shopped around' in other divisions of Sarix in order to fulfill their work norms-and recently Nille has left her position in Sarix to pursue a $\mathrm{PhD}$ at the university where she earned her 'holistic' masters degree.

The practice architecture-the material arrangements, the set-ups of the professional traditions, practical possibilities-prefigure, that is, enables or restrains the enactment of the practitioners' projects in making it harder or easier, more or less difficult to succeed, and so on. In Sarix, the technology-mediated invoicing system effectively blocked the practitioners' ambitions to spend time and invest resources in upholding the team structure. The team structure was only upheld by top-managements' strategy practices, and when the 'proactive' strategy was abandoned, the traditional professional engineering work practices and the management practices of enforcing profitability on an individual basis took sway. In Gitcela, the engineers only paid lip-service to the HRstrategy. The traditional coordinative engineering work practices and the need to optimize effectiveness blocked team-based collaborative practices to develop. 'Gang-staffing' was the natural way to 'go-on' in solving technical problems. The technology-mediated management system was not seen as an obstacle in perusing the project work-it even seemed to sustain their preferred modus operandi. The cellar project was designed in discrete work packages where specialists could receive pre-specified numbers of work hours for their contributions. Thus, the engineers could fulfill their work norms by joining different projects that requested their specialized services-they just had to be in the 'gang-staffing' loop and uphold a professional reputation of being 'accomplished' and 'effective' professionals/colleagues that could deliver their services on time.

\section{Teamwork, professionalism, and collaboration}

In both Sarix and Gitcela, we witness initiatives to reform work organization, to install more collective modes of organizing engineering work practices. In the case of Gitcela 
through centralized and rule governed team initiatives developed by top-management and implemented by HR management. And in the case of Sarix through the ambitions of establishing more innovative and proactive modes of work practices by recruiting 'holistic' engineers. In both cases, we witness the failure of the initiatives. No doubt, the failures can be contributed to many circumstances and the contingencies in the two cases are prevalent-the ecologies of the practices governing engineering consultancy work are indeed complex. As we have spelled out in the previous accounts, one significant element, though, can be found in the predominant way that work is organized and assessed in the (engineering) consultancy sector. The practice architecture thus prefigures practices in specific ways. Individualized accounting systems and performance assessment measured in relation to individual profit contribution does, obviously, not stimulate collective work practices. But another significant component for understanding the failure of the reform initiatives has to do with the individualism inherent in the practice tradition of the engineering profession. Like science, engineering gives priority to individual performance and achievement and degrades collective accomplishments. No doubt, science and engineering are collective endeavors, but collectivity is construed in terms of individuals' coordination among highly specialized individuals who exchange information in predefined patterns of labor division. The engineering projects are thus seen as sequential series of tasks or 'work packages' where engineers of different specialization contribute with incremental solutions to predefined subproblems. These individual contributions are-on a formal level—orchestrated and compiled by the skilled project manager, or more fundamentally on the informal level, by each engineers' coordination efforts in negotiating problems and solutions in the heterogeneous engineering practices. Ethnographic studies of engineering work conducted by James Trevelyan (2007) corroborate this observation. Trevelyan findings suggest that engineering work is characterized by coordinating efforts in relation to clients, managers, fellow-engineers, and others. He writes:

Technical coordination can be described as working with and influencing other people so they conscientiously perform some necessary work in accordance with a mutually agreed schedule. This usually requires three different phases of interaction:

Phase 1: Commissioning the work. The coordinator negotiates an agreement on what has to be done and when it has to be performed.

Phase 2: Execution of the work. Usually it is necessary to be present for some of the time while the work is being done to check that the results (perhaps intermediate) turn out as expected. [...] when the results are unexpected, time and resource limitations or lack of technical understanding may necessitate compromises in the requirements. If possible, the coordinator needs to be able to foresee the technical and other consequences of such a compromise.

Phase 3: Checking the work. The final result needs to be carefully checked to make sure no further work or rectification is needed. (Trevelyan 2007, 194)

Trevelyan's investigations thus demonstrate that the prevailing mode of construing collective work processes in engineering is through coordination. Formal coordination-executed by project management, line officers, or central HRM officers-are of cause common in engineering work. But more pertinently-as the Sarix and Gitcelacases illustrate-informal and local coordination dominates engineering work practices. 
'Coordination usually involves one-on-one relationships with superiors, clients, peers, subordinates, and outsiders'. (Trevelyan 2007, 191).

Construing collective work practices as processes of coordination among individuals-as opposed to collaborative open-ended processes of feedback relations-has consequences. It seems to presuppose that problems are well-defined and that solutions can be most effectively obtained by sequencing individuals' skills and knowledge. It thus construes collective work in a metrics of means-end relations and installs criteria of efficiency and production as the telos of collective work. Rabinow and Bennett (2012, 49-50) characterize this mode of collective work as means-ends maximization:

\begin{abstract}
Expert knowledge is structured and functional only when that which counts as a problem is given in advance, stabilized, and not subject to further questioning. In emergent situations, however, neither goals nor problems are settled, and so technical expertise cannot be effectively marshaled without some adjustment. In many instances, obviously, when goals and problems become settled, technical expertise must be given a useful place within an assemblage. Said another way, routinization is normal but qualitatively different from states of emergence or innovation.
\end{abstract}

Seeing the prevalence of coordinative work within engineering work practices helps us understand why the 'holistic' engineers at Sarix had to resort to instrumental modes of work. The philosophy of the previous management regime in Sarix wanted to replace the narrow technical rationality of traditional engineering and employ new breeds of holistic, innovative, and proactive engineers that can transcend disciplinary bonds and address the complex and ill-defined new problems of the climate change agenda. Due to the COP15 disappointment and an insufficient level of market demands for climate accounts, this philosophy was abandoned and coordination-being the preferred mode of collective work organization in engineering-was reintroduced as the 'natural' fallback position. Likewise, in Gitcela, the coordinative work practices seemed to be the preferred way to 'go on' collaborating. The practical understandings of how to collaborate in effective ways favored coordinative work relations. Although the rhetoric of the HR management construed teamwork as a way of underpinning innovation and efficiency, the dispositions and projects of the engineers inclined them to engage in more traditional coordinative work practices-as did the practice architecture of material arrangements and enforced work procedures in the company.

\title{
Conclusion
}

Team and project work is by no means a clear description of work practices. On the contrary, team and project work functions as a floating signifier that comprise ideals about collaborative work practices and visions of management practices on the one hand and longstanding-discursively and materially molded-professional traditions on the other hand. Our ethnographies about team and project work in the two engineering consultancy companies disclose how the projects and ambitions of actors are mutually interwoven and situated in practice architectures that prefigure actions and they point to the interconnectedness of the practices in complex ecologies or practice bundles. When we entered the two companies, we encountered a manifold of practices bundled together 
in specific ways. We encountered practitioners engaged in either trying to change existing practices or enacting - and thus preserving-existing practices. Engaged in perusing their projects and ends, practitioners used 'teamwork' as a vehicle to transform or preserve work practices. Practitioners wanted to become more innovative, more holistic, more efficient, more effective managers, and so on, and teamwork became a 'media' through which a transformation of existing work practices was envisioned.

Returning to our research questions enables us to understand the dynamics of the studied practices. Our first research question addressed the role of discourses, and we asked how discourses about team and project work affected engineering work practices. In Sarix, we saw how top-management wanted to change the existing reactive engineering culture and spur holistic and proactive ways of work by hiring a new 'breed' of engineers and organizing work in team-structures. In Gitcela, HR-management wanted to optimize human resources through the introduction of team-based work organization. Both of these strategy practices were primarily rhetorically enacted, but they were not underpinned by the traditional professional engineering work practices, and they were effectively blocked by the existing management practices of the technology-mediated invoicing systems. The discourses about teamwork initiated by top-management and HR-management did thus not succeed in changing work practices in either Sarix or Gitcela-they were suffocated in the practice ecology. The few remaining holistic engineers in Sarix tried to uphold their team structure, but we also saw how this endeavor was eroded. The team meetings eventually turned out to be a locus of coordination and not the envisioned innovative space of creative collaboration. Teamwork was in fact only enacted in the semantic space and it had little bearing on the material-economic arrangements and the social-political arrangements of the practices. Although the cultural-discursive arrangements of practices indeed holds performative efficacy (e.g. the team members in Sarix insisted to uphold their team meetings), the team discourse was not strong enough to change existing work practices.

Our second research question asks how technology-mediated management is reconciled in teamwork practices, and thus thematizes the material-economic arrangements of the practices. We have already stressed the role of the technology-mediated invoicing systems as a significant element that directs and structure work and activities in the two companies. Although the invoicing systems by no means make teamwork impossible, it prefigures activities in specific ways. When employees have to account for up to $80 \%$ of their work time in relation to financed project work on a weekly basis, it hardly leaves time for the employees to engage in innovative and holistic teamwork practices. It becomes still more difficult to reconcile teamwork practices with the work demands. The exploratory, creative, collaborative, and holistic elements of teamwork have to give way for means-end maximizing coordinative relations. Influenced by the material-economic arrangements of the invoicing systems, the managements' teamwork visions are transformed into a shallow rhetoric, sidestepped by employees or degenerate to mere coordination. The management practices enforced by the invoicing system thus prefigure the practice architecture in ways that counteract ambitions about organizing work in team structures.

Our third research question asks how team and project work affect engineering professionalism and collaborative work practices. Here, it is important to understand how the predominant ideals of engineering culture favor means-end maximization, efficiency, closure, optimization, stability, predictability, and so on (cf. Bucciarelli \& Kuhn 1997, 
p. 212). Teamwork-understood as an exploratory interdisciplinary or transdisciplinary endeavor-is thus not easily aligned with engineering values and ideals. Although innovation and problem-solving teamwork practices are sought after ideals in engineering, they are mostly construed along lines of coordination between engineers' performing discrete work tasks (cf. Buch \& Andersen 2013b). The predominant practice traditions of engineering interpret teamwork differently than the teamwork ideals proclaimed in management's strategy practices in Sarix and Gitcela. In fact, in Sarix, the strategies were meant to alter the reactive engineering culture: New alternative and holistic engineers were hired to promote the ambitions. And in Gitcela, the strategy should prevent the engineers in indulging in their preferred 'gang-staffing' practices. However, the strategies did not succeed. The social-political arrangements of the engineering profession and the short-term horizon of earning profits in engineering consultancy companies obstructed construing teamwork as holistic and collaborative practices. In Sarix, the holistic engineers hoped for legislative measures that could force private companies to make climate accounts-but as we saw, the wider social-political arrangements of the practice ecology did not support their projects.

Our analysis thus points to the persistence and perseverance of established practices. Practice architectures sediment infrastructures that are not easily changed and-as we have seen-if the new discursive arrangements are not backed by supporting new material-economic and social-political arrangements they will be suffocated in the existing practice ecologies. Establishing more collaborative, innovative, and holistic ecologies of work practices in engineering thus requires a sustainable work environment where discursive-cultural, material-economic, and social-political arrangements are mutual supportive. We do not claim that our two cases are representative of all engineering practices-in fact, the practice-based perspective that we adopt emphasizes the situated and contextual dimensions of practice ecologies. But we do think that our cases touch upon fundamental problems in changing work practices and-specifically in relation to engineering practices-that the engineering profession reproduce traditional meansends rationalities that tend to preserve coordinative work practices. Reform initiatives in engineering education will be needed to overcome professional conservatism, but educational reforms in themselves are not sufficient. Our ethnographies actually demonstrate how the practice ecologies did not sustain holistic engineering practices. The practice theoretical perspective vindicates that reform initiatives must indeed take into consideration the specifics of the practice architecture and the practice ecologies in question and thus consider the interplay between educational initiatives, professional practices, and work practices. However, discussions about the effectiveness of reform initiatives go well beyond the scope of this article. ${ }^{4}$

\section{References}

Alvesson, M. (2004) Knowledge Work and Knowledge-intensive Firms, Oxford, Oxford University Press.

Baker, J. (1999) The Discipline of Teamwork. Participation and Concertive Control, London, SAGE Publications.

Bovbjerg, K. (2006) Teams and Collegiality in Educational Culture, In European Educational Research Journal, Volume 5, Number 3 \& 4, 2006.

Bucciarelli, L., Jacobsen, A., Buch, A. \& Jørgensen, U. (forthcoming) Reforming Engineering Education, Milton Keynes, Morgan Claypool Publishers.

\section{다(1) 9}


Bucciarelli, L. \& Kuhn, S. (1997) Engineering Education and Engineering Practice: Improving the Fit, in Barley, S. \& Orr, J. (eds.) Between Craft and Science. Technical Work in U.S. Settings, Ithaca, IRL Press/Cornell University Press.

Buch, A. (forthcoming) Ideals of 'Holistic Engineering' Meets Professional Work Practices, in Buch, A., Jørgensen, U. and Brodersen S. (eds.): Engineering Professionalism - Engineering Practices in Work and Education.

Buch, A., Jørgensen, U. and Brodersen S. (eds.) (forthcoming) Engineering Professionalism Engineering Practices in Work and Education.

Buch, A. \& Andersen, V. (2013 a) (De)stabilizing Self-identies in Professional Work, Nordic Journal of Working Life Studies, 3(3), 155-173.

Buch, A. \& Andersen, V. (2013b) Collaboration and Coordination in Engineering Work Practices, in Børsen, T. \& Botin, L. (eds.): What is Techno-Antrhopology, Aalborg, Aalborg University Press.

Frodeman, R. et al. (eds.) (2012) The Oxford Handbook of Interdisciplinarity, Oxford, Oxford University Press.

Gherardi, S. (2012) How to Conduct a Practice-based Study. Problems and Methods, Cheltenham, Edward Elgar Publishers.

Haregraves, A. (2000) Changing Teachers, Changing Times: Teachers' Work and Culture in the Postmodern Age, London, Continuum.

Heidegger, M. (1927/2010) Being and Time, New York, State University of New York.

Hekscher, C. \& Adler, P. (2006) The Firm as a Collaborative Community, Oxford, Oxford University Press.

Kemmis, S. \& Grootenboer, P. (2008) Situating Praxis in Practice: Practice Architectures and the Cultural, Social and Material Conditions for Practice, in Kemmis, S. \& Smith, T.J. (eds): Enabling Praxis. Challenges for Education, Rotterdam, Sense Publications.

Kemmis, S. \& Mutton, R. (2012) Education for sustainability (EfS): Practice and practice architectures, in Environmental Education Research, 18(2), 187-207.

Kemmis, S., Wilkinson, J., Edwards-Groves, C., Hardy, I., Grootenboer, P. \& Bristol, L. (2014) Changing Practices, Changing Education, Dordrecht, Springer

Marcus, G. (1995) Ethnography in/of the world system: The emergence of Multi-Sited Ethnography, in Annual Review of Anthropology, 1995. 24: 95-117.

Rabinow, P. \& Bennett, G. (2012) Designing Human Practices. An Experiment with Synthetic Biology, Chicago, Chicago University Press.

Schatzki, T. (2002) The Site of the Social. A Philosophical Account of the Constitution of Social Life and Change, Pennsylvania, Penn State Press.

Schatzki, T. (2010) The Timespace of Human Activity. On Performance, Society, and History as Indeterminate Teleological Events, Lexington, Lexington Books.

Schatzki, T. (2013) The edge of Change. On the emergence, persistence, and dissolution of practices, in Shove, E. \& Spurling, N. (eds.): Sustainable practices. Social Theory and Climate Change, London, Routledge.

Stark, D. (2009) The Sense of Dissonance: Accounts of Worth in Economic Life, Princeton, Princeton University Press.

Trevelyan, J. (2007) Technical Coordination in Engineering Practice, in Journal of Engineering Education, 2007, pp. 191-204.

\section{End notes}

1 Schatzki also refers to the teleological location as 'timespace' (2010) and Kemmis et al. (2014) address teleological locations as 'project'.

2 All names are changed in order to provide anonymity. 
3 We have had the opportunity to perform site visits on a regular basis for almost 1 year between 2011 and 2012 in Sarix and Gitcela. During this period of time, we participated in team meetings, joined the involved engineers when visiting costumers, internal and external partners, or just followed the routines of work and interaction at the office, during lunch breaks, and so on. We have also made more formal interviews with team members, with executive officers and HR-officers. At Sarix, the team members have in addition been doing 'snaplogs' (photo-snapshots and additional logs explaining the significance of their photos). We have made separate interviews with customers and other actors of importance to the sites.

4 For discussions about reform in engineering work and educational practices cf. Buch et al. (forthcoming) and Bucciarelli et al. (forthcoming). 